\title{
Bioprospecting microbial natural product libraries from the marine environment for drug discovery
}

\author{
Xiangyang Liu ${ }^{1,5}$, Elizabeth Ashforth ${ }^{1,5}$, Biao Ren ${ }^{1,2}$, Fuhang Song ${ }^{1}$, Huanqin Dai ${ }^{1}$, Mei Liu ${ }^{1}$, Jian Wang ${ }^{1,3}$, \\ Qiong Xie ${ }^{4}$ and Lixin Zhang ${ }^{1,3}$
}

Marine microorganisms are fascinating resources due to their production of novel natural products with antimicrobial activities. Increases in both the number of new chemical entities found and the substantiation of indigenous marine actinobacteria present a fundamental difficulty in the future discovery of novel antimicrobials, namely dereplication of those compounds already discovered. This review will share our experience on the taxonomic-based construction of a highly diversified and low redundant marine microbial natural product library for high-throughput antibiotic screening. We anticipate that libraries such as these can drive the drug discovery process now and in the future.

The Journal of Antibiotics (2010) 63, 415-422; doi:10.1038/ja.2010.56; published online 7 July 2010

Keywords: antibiotic discovery; dereplication; diversity; high-throughput screening; marine actinomycetes; natural product library; systematics

\section{INTRODUCTION}

Historically, microorganisms have provided the source for the majority of the drugs in use today. ${ }^{1}$ Among these, $45 \%$ are produced by actinomycetes, $38 \%$ by fungi and $17 \%$ by unicellular bacteria. ${ }^{2}$ Since the advent of bacterial genome sequencing in the mid-1990s, it has become apparent that marine actinomycetes have an unrivalled capacity to synthesize bioactive secondary metabolites with a wide spectrum of bioactivities. ${ }^{3-9}$ For example, the genome scanning of the deep-sea actinomycete 'Verrucosispora maris' has resulted in the discovery of $>20$ biosynthetic gene clusters. ${ }^{10}$ Moreover, the application of species richness estimates to actinobacterial diversity data has predicted a value as high as 1353 taxa in the deep sea, with 90\% of these taxa representing novel species and genera. Improved systematics increasingly provides a roadmap to biosynthetic gene clusters and thence to products. As new chemical entities are likely to be discovered from novel actinobacteria, marine actinomycetes are a likely target for improved technological platforms in the search and discovery of novel bioactive compounds.

Many microbial natural products that have reached the market without any chemical modifications are a testimony to the remarkable ability of microorganisms to produce drug-like small molecules. ${ }^{11-14}$ Although still in clinical trails, a feature example of this is salinosporamide A (NPI-0052), a novel anticancer agent found in the exploration of new marine environments. ${ }^{15}$ Natural products, including drugs, are known to occupy a larger and more diverse chemical space than combinatorial chemicals ${ }^{16}$ and completely novel chemical skeletons continue to be discovered among microbial natural products. ${ }^{17}$ In 2008, over 1000 marine natural products were reported. ${ }^{18}$ However, out of the 19 microbial-derived drugs reported in 2008, no natural products from marine microbes were present, signifying the novelty of their systematic exploration. ${ }^{19}$ Currently, $>30$ compounds of marine microbial origin are in clinical or preclinical studies for the treatment of different types of cancer, ${ }^{20-23}$ clearly demonstrating that marine microorganisms have become an essential resource in the discovery of new antibiotic leads. ${ }^{24}$ Quoting Newman and Hill, ${ }^{7}$ 'The search for bioactive metabolites from marine microbes has only just begun'.

The evolution of marine microbial natural product collections and development of high-throughput screening methods have attracted researchers to the use of natural product libraries in drug discovery. ${ }^{25-28}$ These libraries include subsections of crude extracts, pre-fractionated extracts and purified natural products. ${ }^{29}$ A research group in Ireland has developed a two-dimensional chromatographic strategy that includes an automated HPLC-MS fractionation protocol

${ }^{1}$ Chinese Academy of Sciences Key Laboratory of Pathogenic Microbiology \& Immunology, Institute of Microbiology, Chinese Academy of Sciences, Beijing, PR China; ${ }^{2}$ Graduate University, Chinese Academy of Sciences, Beijing, PR China; ${ }^{3}$ South China Sea Institute of Oceanology, Chinese Academy of Sciences, Guangzhou, PR China and ${ }^{4}$ China Astronaut Research and Training Center, Beijing, PR China

5These authors contributed equally to this work.

Correspondence: Dr Q Xie, China Astronaut Research and Training Center, Beijing, PR China.

E-mail: xieqio@yahoo.com.cn or Dr L Zhang, Institute of Microbiology, Chinese Academy of Sciences, Beijing, PR China.

E-mail: zhanglixin@im.ac.cn

This article is dedicated to Dr Arnold L Demain for his 60 years experience as a pioneer, leading advocator and mentor in the field of natural product-based drug discovery. His career is characterized by a sustained level of important discoveries and contributions in several areas of industrial microbiology, including his research on microbial production of immunosuppressive, anti-tumor and anti-fungal drugs as well as on the effect of microgravity on secondary metabolism, an effort that may impact space travelers as well as commercial production strategies.

Received 4 April 2010; accepted 14 April 2010; published online 7 July 2010 


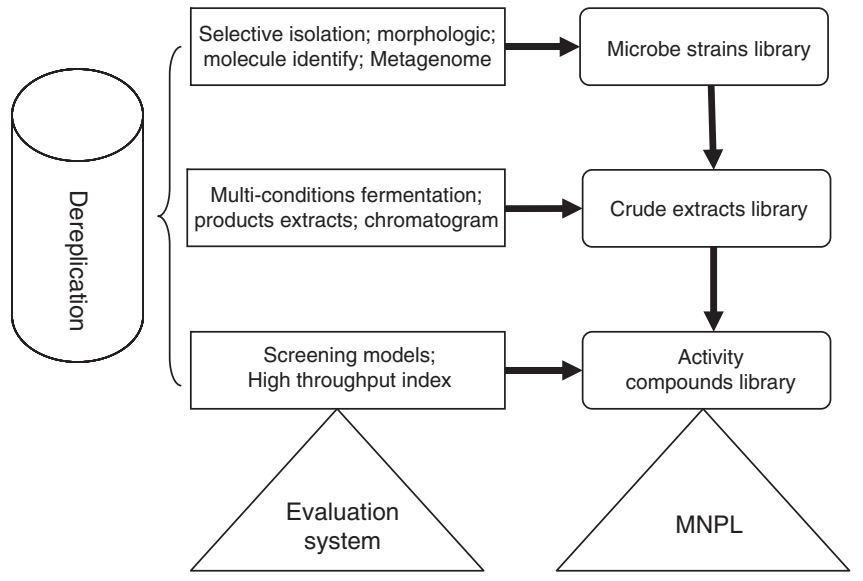

Figure 1 The flow chart of construction of MNPL and evaluation system.

to generate purified marine natural product libraries that are accurately characterized by mass during production to expedite dereplication of known compounds and identification of novel chemotypes. ${ }^{30}$ Although purified natural product libraries are suitable for high-throughput screening, such as single protein assays, the crude extract library and the strain library are also very important for the efficient drug discovery process because they are both cheap and easy to obtain. However, diversification and dereplication of strains and products are central to the construction of a high quality microbial natural product library (MNPL) (Figure 1), saving time and resources for future isolation and purification processes.

\section{BIODIVERSITY OF MARINE MICROBIAL STRAINS}

Recently, large pharmaceutical companies have addressed the premise that the understanding of the chemical diversity of microbial secondary metabolites relies heavily on a good understanding of microbial diversity itself. ${ }^{31}$ They hypothesize that maximizing biological diversity is the key strategy to maximizing chemical diversity. Some companies like Cubist Pharmaceuticals focus on mining cryptic pathways and combinational biosynthesis to generate new secondary metabolites related to existing pharmacophores. ${ }^{32}$ The integrated approaches for maximizing the diversity of microbes in drug discovery programs have been reviewed recently, with selective isolation of novel microorganisms, and metagenomic approaches for, as yet, uncultured microorganisms as keys in diversifying microbial resources and gene sources. ${ }^{11,13,33-35}$

For a culture dependent-bioprospecting strategy, actinobacterial systematics is a guide to successful biodiversity. In 2009, Li's group isolated at least 60 novel species/genera of marine actinomycetes from saline habitats, polluted soils, deep-sea sediments or as symbionts with other organisms. ${ }^{36-95}$ These types of novel environments are important in a natural product library that aims to feature novel active compounds. Goodfellow's group has focused on the isolation of novel actinomycetes. They have isolated 10 novel genera of indigenous marine actinobacteria from acidic and alkaline ecosystems, desert biomes, littoral sediments, hyper-arid deserts and marine habitats. ${ }^{96}$ Indeed, many novel bioactive compounds such as Abyssomicin, Proximicin and Caboxamycin from these new actinomycetes have been isolated. ${ }^{97-99}$ Samples from anaerobic habitats, freshwater habitats, high and low temperature environments and low nutrient sites are also important sources for isolating novel actinomycetes. ${ }^{100}$

Despite the fact that a large diversity of microorganisms are continuously isolated using traditional methods, the majority of microorganisms from the environment are unculturable in the laboratory. ${ }^{101}$ In recent years, many innovative techniques have been developed to efficiently isolate novel microorganisms from the marine biosphere. ${ }^{102-107}$ First, natural substrates containing living cells as the source of nutrients and potential signaling agents can be used to stimulate the microorganisms that are difficult to culture. This method uses membrane systems that allow the diffusion of small molecules but prevent contamination by undesired bacteria. This strategy has been described for the isolation of marine bacteria using diffusion chambers incubated in an aquarium in the presence of other microorganisms. ${ }^{101}$ Using this approach, a large number of diverse colonies can be recovered, although new phylotypes may not necessarily be obtained. The addition of factors such as pyruvate, cyclic AMP and homoserine lactones have also been shown to instigate the generation of greater numbers of microorganisms. ${ }^{13}$ Second, a selected group of strains can be cultivated using oligotrophic isolation media, such as the use of seawater-based media for marine organisms, allowing only growth of selectively adapted microbes and, at the same time, inhibiting the majority of the natural population. Third, highthroughput methods in which conventional Petri dishes are replaced by microtiter plates have been developed to obtain the untapped microbial diversity. Connon and Giovanonni have developed a highthroughput method using low nutrient medium to isolate and cultivated many marine microorganisms, ${ }^{104,106}$ including many uncultured bacteria from bacterioplankton communities. ${ }^{108,109}$ Another high-throughput technique involving encapsulation of single cells using gel microdroplets was developed by Diversa Corporation (San Diego, CA, USA). ${ }^{110}$ This approach combines cultivation of the encapsulated cells under low nutrient flux conditions, followed by flow cytometry to detect microdroplets containing microcolonies. Despite the fact that high dilution and high-throughput methods have been used to cultivate more microorganisms, it remains unclear whether the microorganisms obtained are able to produce novel secondary metabolites. It is obvious, however, that these methods are valuable and need further exploration.

\section{BIODIVERSITY OF MARINE MICROBIAL GENE RESOURCES}

Metagenomics is promising in efforts to gain access to uncultured microorganisms. The analysis of DNA isolated from environmental samples has proved very useful for these bacteria, which may be a new source of novel antibiotics. ${ }^{111-113}$ For example, metagenomes of sponge microbial communities have been shown to contain genes and gene clusters typical for the biosynthesis of biologically active natural products. ${ }^{114}$ Heterologous expression approaches have also led to the isolation of secondary metabolism gene clusters from uncultured microbial symbionts of marine invertebrates, and soil metagenomic libraries. In the metagenomic approach, isolated DNA is ligated into bacterial artificial chromosome vectors, low copy plasmids that can contain large DNA inserts up to $300 \mathrm{~kb} .{ }^{115}$ The bacterial artificial chromosome vectors are then subsequently transformed into host microorganisms such as Escherichia coli, Streptomyces lividans and Pseudomonas putida. ${ }^{116}$ The resulting clones can then be screened for biological activity or alternatively probed for sequences of interest. ${ }^{117}$ For example, Gillespie et al. ${ }^{118}$ have isolated the antibiotics turbomycin A and B from a metagenomic library of soil microbial DNA. Many other biologically active compounds such as amino acids and fatty acids have been obtained by Singh and Pelaez. ${ }^{31}$ We have constructed a metagenomic library of about 30000 clones, of which 16 clones were identified as having interesting biological activity after screening for lipase activity (data not published). It is noteworthy that metagenomic approaches will not only activate the research field 
of marine microbial diversity but will also provide opportunity for the genetic conservation of marine microorganisms. ${ }^{112}$ Undoubtedly, metagenome analysis technology combined with high-throughput screening will bring innovation to the drug discovery.

\section{BIODIVERSITY OF MICROBIAL PRODUCTS}

Although the biosynthetic and regulative crosstalk of secondary metabolite biosynthesis is complex within and between microorganisms, all levels can be influenced by imitating natural environmental changes. Use of this method to release nature's chemical diversity has been termed 'one strain, many active compounds.' ${ }^{19}$ Bode et al. ${ }^{119}$ used the systematic alteration of easily accessible cultivation parameters to increase the number of secondary metabolites from a single organism. Very small changes in cultivation conditions resulted in a complete shift in the metabolic profiles of the microorganisms. For example, in the presence of different supplements, various acyl and phenyl $\alpha$-L-rhamnopyranosides were produced by Streptomyces griseoviridis. ${ }^{120}$ Bills et al. ${ }^{121}$ have used bacterial micro-fermentators for fungal growth in nutritional arrays, and the results indicate that the protocols can be used to pre-select strains and their growth conditions for scaling up.

Development and testing of new culture media for the maximum expression of secondary metabolites is as important as genome-guided chemical diversity in the construction process of an MNPL. Secondary metabolite production in microbes is strongly influenced by nutritional factors and growth conditions. However, without prior knowledge of the preferred growth conditions for a given microorganism, random assignment of media to strains may generate an inefficient redundancy of metabolites or strains lacking the relevant levels of secondary metabolites. An optimization of 'one strain, many active compounds' can be used together with 'fingerprint' methods (HPLC and nuclear magnetic resonance) for the optimization/selection of culture media for high-throughput fermentation of novel strains. Tormo et al. ${ }^{122}$ developed a method for the selection of production media for actinomycete strains based on their metabolite HPLC profiles, and three media types that yielded the highest metabolite diversity and least overlapping HPLC profiles were selected for largescale fermentation. Researchers at Merck use eight different types of media for the cultivation of strains to make product library, from which new antimicrobial compounds such as platensimycin, platencin, philipimycin, fluvirucins, lucensimycins and okilactomycin have been isolated. ${ }^{123-128}$ We used 10 different media (Table 1) for the cultivation of novel actinomycetes. ${ }^{129-131}$ It was found that this was successful in obtaining a higher positive hit rate $(70 \%)$ than the

Table 1 The fingerprint characteristic of 10 culture medium for MS098

\begin{tabular}{lrcrrr}
\hline Medium & Peaks & Area & DI (\%) & QI (\%) & D/Q (\%) \\
\hline 9A & 33 & 140427.7 & 6.42 & 1.39 & 2.65 \\
NM2 & 53 & 446167.5 & 10.31 & 4.42 & 5.89 \\
NM1 & 69 & 561396.1 & 13.42 & 5.56 & 7.52 \\
MPG & 87 & 1093319 & 16.93 & 10.82 & 12.35 \\
M21 & 74 & 4980134 & 14.40 & 49.28 & 40.56 \\
M12 & 51 & 445540.2 & 9.92 & 4.41 & 5.79 \\
M004 & 48 & 253674.4 & 9.34 & 2.51 & 4.21 \\
M001 & 33 & 1461252 & 6.42 & 14.46 & 12.45 \\
GOT & 40 & 79100.25 & 7.78 & 0.78 & 2.53 \\
FR & 77 & 644646.5 & 14.98 & 6.38 & 8.53 \\
Total & 514 & 10105658 & & & \\
\hline
\end{tabular}

Table 2 Hits from our library by high-throughput screening model

\begin{tabular}{lcccccc}
\hline Assays & $C A$ & $S C A$ & $B C G$ & $B P L$ & $M R S A$ & $14-3-3$ \\
\hline Extracts & 14800 & 8000 & 10800 & 4000 & 12800 & 10000 \\
Hits & 84 & 39 & 97 & 42 & 100 & 35 \\
Hit rates (\%) & 0.32 & 0.48 & 0.89 & 1.05 & 0.78 & 0.35 \\
\hline
\end{tabular}

historical hit rate (1\%) with the same screening methods (Table 2). Till now, 13 novel active compounds have been isolated from the microbial natural products library, which include those from fungi. ${ }^{132,133}$

\section{DEREPLICATION OF STRAINS AND CRUDE EXTRACTS}

Discrimination between previously tested or recovered microorganisms (dereplication) is a primary issue for a high quality-MNPL. It is not practical to characterize the large numbers of unknown strains within a library using polyphasic taxonomic approaches. Therefore, tools such as color-grouping, rep-PCR, single strand conformation polymorphism and analytical chemistry (FTIR, MALDI-TOF, pyrolysis mass spectrometry) have been developed to estimate diversity and dereplicate strains. It is noteworthy that strains similar according to sequence analysis but unique according to REP analysis could produce different surfactant mixtures under same growth conditions. ${ }^{134}$ Thus, $16 \mathrm{~S}$ rRNA gene database commonly used for determining phylogenetic relationships may miss diversity in microbial products (for example biosurfactants and antibiotics) that are made by closely related isolates. One can amplify the rep-PCR target bands by the employment of genus special primers when we obtained active strains to make the dereplication. By using this method, we isolated a novel bioactive compound (3304X) from a marine fungus Aspergillus fumigatus MF330 (data not shown). Pyrolysis mass spectrometry is a whole-cell fingerprinting technique that enables the rapid and reproducible sorting of microorganisms using small samples in a fully automated system. ${ }^{135}$ It has been successfully used to distinguish nitrile-hydrolysing strains of actinomycetes, revealing a significant variation within pyrogroups containing strains with same genotypic characteristics, thus demonstrating its discriminatory capacity at the infraspecies level. ${ }^{136}$ Intact-cell MALDI-TOF mass spectrometry has been used for the rapid clustering of 456 strains based on their proteomes, resolving 11 separate groups and permitting the rapid identification of isolates for dereplication and the selection of rare species. ${ }^{137}$ In addition, MALDI-TOF MS can also be used for the dereplication of complex microorganism communities based on the mass spectra of constantly expressed high-abundant proteins, such as ribosomal proteins of 2000-20000 Da. ${ }^{138}$ The color-grouping procedure establishing the taxon richness is limited when used to distinguish between different pigments. Unfortunately, this means that it is not possible to generate cumulative databases to compare the results of independent studies on indigenous populations of streptomycetes. Recently, a computer-assisted color-grouping method corresponding with rep-PCR data has been developed for dereplicating large numbers of alkaliphilic streptomycetes. ${ }^{139}$ This computer-assisted numerical analysis method is a cheap and reliable alternative to molecular and chemical dereplication methods because it offers a minimal taxon description method for large numbers of isolates.

Another issue is the dereplication of chemical compounds from the library. Tandem analytical techniques such as MS/MS/MS, GC-EI/MS, HPLC-SPE-NMR, LC-MS-MS and LC-NMR have also been developed for dereplication of natural products. ${ }^{140-145}$ However, these methods can lead to false compound identifications because there 
are uncertainties in the observed pseudomolecular ions such as $\mathrm{MH}^{+}$, $\mathrm{MNa}^{+}, \mathrm{MK}^{+}, \mathrm{MNH}_{4}{ }^{+}, \mathrm{MCH}_{4} \mathrm{CN}^{+}$etc. ${ }^{146}$ To speed up dereplication, Bitzer and Bradshaw ${ }^{147,148}$ have used a reference library-supported analytical technique for the dereplication of crude extracts and prefractionated samples. However, this kind of approach is not always viable due to fact that the databases needed are not widely available. Recently, Munro's group has developed a new technology using HPLC profiling with biological evaluation followed by capillary probe NMR spectroscopy/ESMS/UV combined with NMR database (AntiMarin) evaluation, which reduces the crude extract requirement for dereplication to submilligram quantities. ${ }^{149}$ By this method, they isolated a new peptaibol chrysaibol, from a New Zealand isolate of the mycoparasitic fungus Sepedonium chrysospermum. ${ }^{150}$ It is worthy to note that the method developed by Munro et al. will be effective for crude extract evaluation, isolation and dereplication.

Last but not the least is the dereplication of positive hits with the development of target biosensor organisms (Candida albicans and Staphylococcus aureus) with differential whole-cell sensitivity. Cubist Pharmaceuticals constructed a multi-drug resistant E. coli strain, which carries resistance markers for 17 of the most frequently produced antibiotics. ${ }^{32}$ Thus, a comparison of extract activities against sensitive and resistant $E$. coli strains will allow researchers to rapidly prioritize extracts whose activities cannot be accounted for by any of these 17 antibiotics. We also used this strain to dereplicate the active extracts from our natural product library. In addition, we have developed a streptomycin- and rifampicin-resistant Mycobacterium smegmatis strain for screening of novel antituberculous compounds. Encouragingly, some extracts, while not active against the sensitive strain, are active against the resistant strain, leading to the rapid discovery of novel and specific active compounds.

\section{EVALUATION OF THE MICROBIAL STRAIN AND PRODUCT LIBRARY}

Recent advances in molecular techniques have led to the development of databases that describe microbial diversity at the genetic level based on 16S rRNA sequence diversity. ${ }^{151-153}$ This mass of information and the highly conserved nature of the $16 \mathrm{~S}$ rRNA gene can be used to identify and evaluate the diversity of the MNPL, and dereplicate genetically similar microorganisms. ${ }^{154}$ As well as general diversity, specific primers can be used to evaluate samples to target actinobacteria that have not been described earlier. ${ }^{155}$ With specific primers, Stach et al. ${ }^{156}$ could detect an actinobacterial diversity of at least one order of magnitude higher than those obtained with current culturebased techniques. In addition, denaturing gradient gel electrophoresis is another molecular tool used to detect the phylogenetic 'fingerprint' of diverse marine microorganisms. ${ }^{157-159}$ It is worthy to note that the addition of new 16S rRNA gene sequence information and the changes in phylogenetic positions of some taxa influence decisions about which $16 \mathrm{~S}$ rRNA nucleotides to define as taxon specific. On the basis of 10 years of development in the identification of actinomycetes, Zhi et al. ${ }^{160}$ redefinied the higher ranks of the class Actinobacteria, with the proposal of two new suborders, four new families and emended descriptions of the existing higher taxa.

The quality of the microbial products in the library in terms of their physicochemical properties is critical for their development into useable drugs. Lipinski's rule of five, focusing on the MW and structure complexity, has been used as a rule of thumb to indicate whether a molecule is likely to be orally bioavailable (bioactive). ${ }^{161}$ However, various authors, including Lipinski, have pointed out that many antibacterial compounds have exceptions to these rules primarily because of their higher MW and polarity. For example, both daptomycin and cyclosporine A have MWs of 1620 and 1202, respectively, which is larger than Lipinski's ideal value of $500 .{ }^{162,163}$ Leeson and Davis ${ }^{164}$ also showed a deviation in anti-infective drugs toward higher MW and increased polarity. Another example is the result from Ganesan's group that some 24 unique natural products in the 1970-2006 period violated Lipinski's rules. ${ }^{19}$ Of particular interest is O'Shea's results that the unique physicochemical property space required for antibacterial active compounds, and especially Gramnegative antibacterials, must be taken into account during highthroughput screening when identifying hits with whole-cell activity. ${ }^{165}$ These physicochemical properties are paramount in the uptake of compounds through the cell membrane and therefore the drugability of the compound.

Evaluating the potential of a library of compounds and identifying those with new activities and/or new structure is the basis of quality evaluation. Targeted high-throughput screening methods are important for the speed and accuracy of identification of novel antimicrobials; for example, in the case of platensimycin, paltemycin and MAC13243.123,124,166,167 We have focused on systematic biology to develop high-throughput synergy screening for synergistic antifungal compounds (Figure 2) ${ }^{12}$ In our group, special target screening ( $p$ ABA synthesis inhibition model; 14-3-3 protein binding model and AHLs quorum-sensing inhibition model) and the architecture-based screening (enediyne synthesis model) are used to give a comprehensive active evaluation of the compounds in the MNPL. From these evaluation models, many crude extracts or purified compounds were obtained as positive hits (Table 2). In addition for evaluation purposes, it is worthy to note that these screening assays also provide mode of action hypothesis from the crude extracts.

Novel gene clusters such as polyketide synthases (PKSs) and nonribosomal peptide synthetases (NRPSs) in the library indicate the likelihood of novel compounds being produced. Ayuso-Sacido and Genilloud $^{168}$ designed new PCR primers specifically targeted to amplify NRPS and PKS-I gene sequences from actinomycetes. By using primers designed by Ayuso-Sacido and Courtois, Goodfellow's group identified five strains with NRPS and PKS gene clusters from 38 marine actinomycetes. ${ }^{96}$ By using Ayuso-Sacido's primers, we have made a primary evaluation of the MNPL, where 14 strains with PKSs and NRPSs were identified from the randomly selected strain library and 27 PKSs and NRPSs were identified from the megagenomic library (Table 3). The Mohanty group has developed an NRPS-PKS software and organized the sequence information on various experimentally characterized NRPS and PKS gene clusters in the form of searchable computerized databases. ${ }^{169}$ This approach may facilitate the evaluation of the presence of NRPS and PKS gene clusters in the strain library. Recently, genome mining has been used for the successful induction of a silent metabolic pathway in the important model organism Aspergillus nidulans, which led to the discovery of novel PKS-NRPS hybrid metabolites. ${ }^{170}$ This method can also align strains based on genus and provides information on the metabolites and functional compounds as many metabolites of actinomycetes are produced by PKSs and NRPSs. ${ }^{135}$ Merck researchers have developed a new fingerprinting approach based on the restriction analysis of these PKS and NRPS-amplified sequences, and observed a good relationship between the presence of PKS-I, PKS-II and NRPS sequences and the antimicrobial activities in Streptomyces. ${ }^{135}$

In summary, the combined results of molecular evaluation techniques (16S universal and specific primers, PKS and NRPS gene clusters), physicochemical properties of compounds, and activities in vivo and in whole-cell assays determine the novelty and quality of the marine microbial strain and product library. 


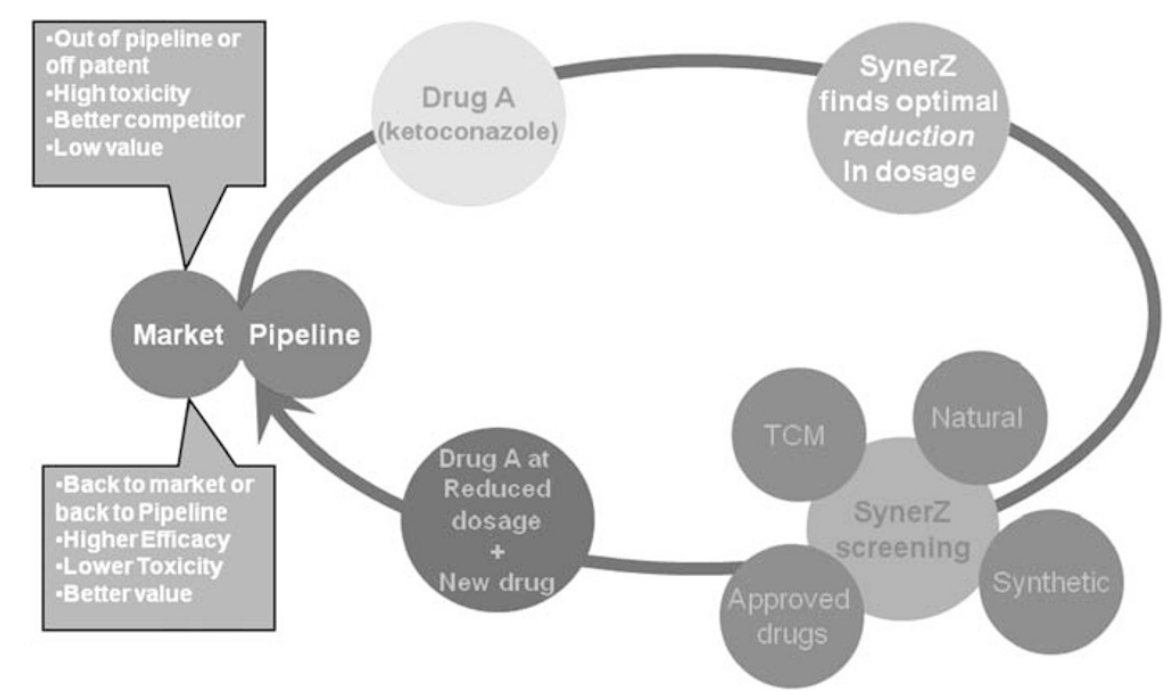

Figure 2 Schematic representation of high-throughput methods applied to the process of drug discovery from natural resources. A full color version of this figure is available at The Journal of Antibiotics journal online.

Table 3 The PKS and NRPS screening results

\begin{tabular}{lcccc}
\hline & PKSI & PKSII & NRPS & Halogenase \\
\hline New strain library (100) & 8 & 3 & 3 & \\
Metagenomic library & 18 & & 9 & 5 \\
\hline
\end{tabular}

Abbreviations: NRPS, nonribosomal peptide synthetase; PKS, polyketide synthase.

\section{CONCLUSION}

This review expresses our long-term interest in the construction of a high-quality microbial natural product library in the facilitation of high-throughput screening programs for the drug discovery process. In the initial phase, it is hard to say whether the active compounds obtained from our natural product library are novel; therefore, great care must be taken to dereplicate known compounds before comparing with the dictionary of the natural product library, to identify which compounds are truly novel. Although tools for the evaluation of the microbial natural product library have been developed and can be directly applied to maintain the quality of the library, the initial biodiversity of the strains used for the construction of the library is of ultimate importance to reduce the redundancy of chemical compounds. Selection of novel marine actinomycetes combined with the employment of a high-throughput fermentation method maximizes the biodiversity foundation of the library.

\section{ACKNOWLEDGEMENTS}

We thank Professor Yoshikazu Takahashi for giving us the opportunity to prepare this review. This work was supported in part by grants from National 863 Project (2006AA09Z402, 2007AA09Z443), Key Project for International Cooperation (2007DFB31620), National Natural Science Foundation of China (30973665, 30700015, 30901849, 30911120484, 81011120046 and 30911120483), National Key Technology R\&D Program (2007BAI26B02), the CAS Pillar Program (KSCX2-YW-R-164), Important National Science \& Technology Specific Projects (2008ZX09401-05, 2009ZX09302-004). LZ received funding from the Hundred Talents Program.

1 Demain, A. L. \& Sanchez, S. Microbial drug discovery: 80 years of progress. J. Antibiot. 62, 5-16 (2009).

2 Berdy, J. Bioactive microbial metabolites-a personal view. J. Antibiot. 58, 1-26 (2005).
3 Venter, J. C. et al. Environmental genome shotgun sequencing of the Sargasso Sea. Science 304, 66-74 (2004).

4 Hong, K. et al. Actinomycetes for marine drug discovery isolated from mangrove soils and plants in China. Mar. Drugs 7, 24-44 (2009).

5 Gandhimathi, R. et al. Antimicrobial potential of sponge associated marine actinomycetes. J. Mycol. Med. 18, 16-22 (2008).

6 Bull, A. T. \& Stach, J. E. Marine actinobacteria: new opportunities for natural product search and discovery. Trends Microbiol. 15, 491-499 (2007).

7 Newman, D. J. \& Hill, R. T. New drugs from marine microbes: the tide is turning. J. Ind. Microbiol. Biotechnol. 33, 539-544 (2006).

8 Jensen, P. R., Mincer, T. J., Williams, P. G. \& Fenical, W. Marine actinomycete diversity and natural product discovery. Anton. Leeuw. Int. J. G. 87, 43-48 (2005).

9 Jensen, P. R. \& Fenical, W. in Natural Products: Drug Discovery and Therapeutics Medicines (eds Zhang, L. \& Demain, A.L.) 315-328 (Humana Press, Totowa, NJ, 2005).

10 Riedlinger, J. et al. Abyssomicins, inhibitors of the para-aminobenzoic acid pathway produced by the marine Verrucosispora strain AB-18-032. J. Antibiot. 57, 271-279 (2004).

11 Knight, V. et al. Diversifying microbial natural products for drug discovery. Appl. Microbiol. Biotechnol. 62, 446-458 (2003).

12 Zhang, L. X. et al. High-throughput synergy screening identifies microbial metabolites as combination agents for the treatment of fungal infections. Proc. Natl Acad. Sci. USA 104, 4606-4611 (2007).

13 Zhang, L. X. et al. Exploring novel bioactive compounds from marine microbes. Curr. Opin. Microbiol. 8, 276-281 (2005).

14 Bull, A. T. \& Stach, J. E. Marine actinobacteria: new opportunities for natural product search and discovery. Trends Microbiol. 15, 491-499 (2007).

15 Fenical, W. et al. Discovery and development of the anticancer agent salinosporamide A (NPI-0052). Bioorg. Med. Chem. 17, 2175-2180 (2009).

16 Feher, M. \& Schmidt, J. M. Property distributions: differences between drugs, natural products, and molecules from combinatorial chemistry. J. Chem. Inf. Comp. Sci. 43, 218-227 (2003).

17 Newman, D. J. \& Cragg, G. M. Natural products as sources of new drugs over the last 25 years. J. Nat. Prod. 70, 461-477 (2007).

18 Blunt, J. W., Copp, B. R., Munro, M. H., Northcote, P. T. \& Prinsep, M. R. Marine natural products. Nat. Prod. Rep. 27, 165-237 (2010).

19 Ganesan, A. The impact of natural products upon modern drug discovery. Curr. Opin. Chem. Biol. 12, 306-317 (2008).

20 Simmons, T. L., Andrianasolo, E., McPhail, K., Flatt, P. \& Gerwick, W. H. Marine natural products as anticancer drugs. Mol. Cancer Ther. 4, 333-342 (2005).

21 Mayer, A. M. S. \& Gustafson, K. R. Marine pharmacology in 2005-2006: antitumour and cytotoxic compounds. Eur. J. Cancer 44, 2357-2387 (2008).

22 Salomon, C. E., Magarvey, N. A. \& Sherman, D. H. Merging the potential of microbial genetics with biological and chemical diversity: an even brighter future for marine natural product drug discovery. Nat. Prod. Rep. 21, 105-121 (2004).

23 Gordaliza, M. Natural products as leads to anticancer drugs. Clin. Transl. Oncol. 9, 767-776 (2007).

24 Kasanah, N. \& Hamann, M. T. Development of antibiotics and the future of marine microorganisms to stem the tide of antibiotic resistance. Curr. Opin. Investig. Drugs 5, 827-837 (2004).

25 Larsson, J., Gottfries, J., Muresan, S. \& Backlund, A. ChemGPS-NP: tuned for navigation in biologically relevant chemical space. J. Nat. Prod. 70, 789-794 (2007). 
26 Koch, M. A. et al. Charting biologically relevant chemical space: a structural classification of natural products (SCONP). Proc. Natl Acad. Sci. USA 102, 17272-17277 (2005).

27 Koehn, F. E. \& Carter, G. T. The evolving role of natural products in drug discovery. Nat. Rev. Drug Discov. 4, 206-220 (2005).

28 Mishra, K. P., Ganju, L., Sairam, M., Banerjee, P. K. \& Sawhney, R. C. A review of high throughput technology for the screening of natural products. Biomed. Pharmacother. 62, 94-98 (2008).

29 Koehn, F. E. High impact technologies for natural products screening. Prog. Drug Res. 65, 175 177-210 (2008).

30 Bugni, T. S. et al. Marine natural product libraries for high-throughput screening and rapid drug discovery. J. Nat. Prod. 71, 1095-1098 (2008).

31 Singh, S. B. \& Pelaez, F. Biodiversity, chemical diversity and drug discovery. Prog. Drug Res. 65, 141 143-174 (2008)

32 Baltz, R. H. Renaissance in antibacterial discovery from actinomycetes. Curr. Opin. Pharmacol. 8, 557-563 (2008).

33 Bian, J., Song, F. \& Zhang, L. Strategies on the construction of high-quality microbial natural product library-a review. Wei Sheng Wu Xue Bao 48, 1132-1137 (2008).

34 Wagner-Dobler, I., Beil, W., Lang, S., Meiners, M. \& Laatsch, H. Integrated approach to explore the potential of marine microorganisms for the production of bioactive metabolites. Adv. Biochem. Eng. Biotechnol. 74, 207-238 (2002).

35 Zhang, L. in Natural Products: Drug Discovery and Therapeutics Medicines (eds Zhang, L. \& Demain, A.L.) 33-56 (Humana Press, Totowa, NJ, 2005).

36 Qin, S. et al. Actinomadura flavalba sp. nov. an endophytic actinomycete isolated from leaves of Maytenus austroyunnanensis. Int. J. Syst. Evol. Microbiol. 59, 2453-2457 (2009).

37 Yuan, L. J. et al. Actinopolymorpha cephalotaxisp. nov., a novel actinomycete isolated from rhizosphere soil of the plant Cephalotaxus fortunei. Int. J. Syst. Evol. Microbiol. 60, 51-54 (2010).

38 Wang, Y. et al. Aidingimonas halophila gen. nov., sp. nov., a moderately halophilic bacterium isolated from a salt lake. Int. J. Syst. Evol. Microbiol. 59, 3088-3094 (2009)

39 Tang, S. K. et al. Amycolatopsis halophila sp. nov., a halophilic actinomycete isolated from a salt lake. Int. J. Syst. Evol. Microbiol. 60 (Pt 5), 1073-1078 (2009).

40 Wang, Y. N. et al. Amycolicicoccus subflavus gen. nov., sp. nov., an actinomycete isolated from a saline soil contaminated by crude oil. Int. J. Syst. Evol. Microbiol. 60, 638-643 (2010).

41 Chen, Y. G. et al. Bacillus neizhouensis sp. nov., a halophilic marine bacterium isolated from a sea anemone. Int. J. Syst. Evol. Microbiol. 59, 3035-3039 (2009).

$42 \mathrm{Li}$, J. et al. Dietzia schimae sp. nov. and Dietzia cercidiphylli sp. nov., from surfacesterilized plant tissues. Int. J. Syst. Evol. Microbiol. 58, 2549-2554 (2008).

43 Tang, S. K. et al. Georgenia halophila sp. nov., a novel halophilic actinobacterium isolated from a salt lake. Int. J. Syst. Evol. Microbiol. 60, 1317-1421 (2010).

44 Qin, S. et al. Glycomyces endophyticus sp. nov., an endophytic actinomycete isolated from the root of Carex baccans Nees. Int. J. Syst. Evol. Microbiol. 58, 2525-2528 (2008)

45 Qin, S. et al. Glycomyces scopariae sp. nov. and Glycomyces mayteni sp. nov., isolated from medicinal plants in China. Int. J. Syst. Evol. Microbiol. 59, 1023-1027 (2009).

46 Tang, S. K. et al. Gracilibacillus saliphilus sp. nov., a moderately halophilic bacterium isolated from a salt lake. Int. J. Syst. Evol. Microbiol. 59, 1620-1624 (2009).

47 Tang, S. K. et al. Haloactinobacterium album gen. nov., sp. nov. a novel halophilic actinobacterium isolated from a salt lake in China, with proposal of Ruaniaceae fam. nov. Int. J. Syst. Evol. Microbiol. (e-pub ahead of print 23 October 2009; doi:10.1099/ijs.0.018440-0).

48 Chen, Y. G. et al. Halobacillus salsuginis sp. nov., a moderately halophilic bacterium from a subterranean brine. Int. J. Syst. Evol. Microbiol. 59, 2505-2509 (2009).

49 Tang, S. K. et al. Haloechinothrix alba gen. nov., sp. nov., a novel halophilic filamentous actinomycete of the suborder Pseudonocardineae. Int. J. Syst. Evol. Microbiol. (e-pub ahead of print 30 October 2009; doi:10.1099/ijs.0.018531-0).

50 Guan, T. W. et al. Haloglycomyces albus gen. nov., sp. nov., a halophilic, filamentous actinomycete of the family Glycomycetaceae. Int. J. Syst. Evol. Microbiol. 59, 1297-1301 (2009)

51 Chen, Y. G. et al. Halomonas zhanjiangensis sp. nov., a halophilic bacterium isolated from a sea urchin. Int. J. Syst. Evol. Microbiol. 59, 2888-2893 (2009).

$52 \mathrm{Li}$, J. et al. Herbidospora osyris sp. nov., isolated from surface-sterilized tissue of Osyris wightiana Wall. ex Wight. Int. J. Syst. Evol. Microbiol. 59, 3123-3127 (2009).

$53 \mathrm{Wu}, \mathrm{Y}$. et al. Isoptericola jiangsuensis sp. nov., a chitin-degrading bacterium. Int. J. Syst. Evol. Microbiol. 60 (Pt 4), 904-908 (2009).

54 Guo, X. Q. et al. Jeotgalicoccus huakuii sp. nov., a halotolerant bacterium isolated from the seaside soil. Int. J. Syst. Evol. Microbiol. 60, 1307-1310 (2010).

55 Chen, Y. G. et al. Jeotgalicoccus marinus sp. nov., a marine bacterium isolated from a sea urchin. Int. J. Syst. Evol. Microbiol. 59, 1625-1629 (2009).

56 Qin, S. et al. Jiangella alba sp. nov., an endophytic actinomycete isolated from the stem of Maytenus austroyunnanensis. Int. J. Syst. Evol. Microbiol. 59, 2162-2165 (2009)

$57 \mathrm{Li}$, J. et al. Kineosporia mesophila sp. nov., isolated from surface-sterilized stems of Tripterygium wilfordii. Int. J. Syst. Evol. Microbiol. 59, 3150-3154 (2009).

58 Tang, S. K. et al. Kocuria halotolerans sp. nov., an actinobacterium isolated from a saline soil in China. Int. J. Syst. Evol. Microbiol. 59, 1316-1320 (2009).

59 Tang, S. K. et al. Kocuria halotolerans sp. nov., an actinobacterium isolated from a saline soil in China. Int. J. Syst. Evol. Microbiol. 59, 1316-1320 (2009).
60 Zhang, J. et al. Laceyella tengchongensis sp. nov., a thermophilic strain isolated from the Big Empty Volcano. Int. J. Syst. Evol. Microbiol. (e-pub ahead of print 13 November 2009; doi:10.1099/ijs.0.011767-0).

61 Tian, X. P. et al. Marinactinospora thermotolerans gen. nov., sp. nov., a marine actinomycete isolated from a sediment in the northern South China Sea. Int. J. Syst. Evol. Microbiol. 59, 948-952 (2009).

62 Wang, Y. et al. Marinococcus luteus sp. nov., a halotolerant bacterium isolated from a salt lake, and emended description of the genus Marinococcus. Int. J. Syst. Evol. Microbiol. 59, 2875-2879 (2009)

63 Chen, H. H. et al. Micrococcus endophyticus sp. nov., isolated from surface-sterilized Aquilaria sinensis roots. Int. J. Syst. Evol. Microbiol. 59, 1070-1075 (2009).

64 Zhao, G. Z. et al. Micrococcus yunnanensis sp. nov., a novel actinobacterium isolated from surface-sterilized Polyspora axillaris roots. Int. J. Syst. Evol. Microbiol. 59, 2383-2387 (2009)

65 Chen, Y. G. et al. Nocardiopsis litoralis sp. nov., a halophilic marine actinomycete isolated from a sea anemone. Int. J. Syst. Evol. Microbiol. 59, 2708-2713 (2009).

66 Qin, S. et al. Nonomuraea antimicrobica sp. nov., an endophytic actinomycete isolated from a leaf of Maytenus austroyunnanensis. Int. J. Syst. Evol. Microbiol. 59, 2747-2751 (2009).

67 Wang, Y. et al. Paracoccus saliphilus sp. nov, a halophilic bacterium isolated from a saline soil. Int. J. Syst. Evol. Microbiol. 59, 1924-1928 (2009).

68 Chen, Y. G. et al. Paraliobacillus quinghaiensis sp. nov., isolated from salt-lake sediment in China. Int. J. Syst. Evol. Microbiol. 59, 28-33 (2009).

69 Chen, Y. G. et al. Pigmentiphaga litoralis sp. nov., a facultatively anaerobic bacterium isolated from a tidal flat sediment. Int. J. Syst. Evol. Microbiol. 59, 521-525 (2009).

70 Qin, S. et al. Plantactinospora mayteni gen. nov., sp. nov., a member of the family Micromonosporaceae. Int. J. Syst. Evol. Microbiol. 59, 2527-2533 (2009).

71 Chen, Y. G. et al. Pontibacillus halophilus sp. nov., a moderately halophilic bacterium isolated from a sea urchin. Int. J. Syst. Evol. Microbiol. 59, 1635-1639 (2009).

72 Chen, Y. G. et al. Pontibacillus litoralis sp. nov., a facultatively anaerobic bacterium isolated from a sea anemone, and emended description of the genus Pontibacillus. Int. J. Syst. Evol. Microbiol. 60, 560-565 (2010).

$73 \mathrm{Li}, \mathrm{Y}$. et al. Prauserella salsuginis sp. nov., Prauserella flava sp. nov., Prauserella aidingensis sp. nov. and Prauserella sediminis sp. nov., isolated from a salt lake. Int. J. Syst. Evol. Microbiol. 59, 2923-2928 (2009).

74 Chen, H. H. et al. Pseudonocardia endophytica sp. nov., isolated from the pharmaceutical plant Lobelia clavata. Int. J. Syst. Evol. Microbiol. 59, 559-563 (2009).

75 Qin, S. et al. Pseudonocardia tropica sp. nov., a novel endophytic actinomycete isolated from the stem of Maytenus austroyunnanensis. Int. J. Syst. Evol. Microbiol. (e-pub ahead of print 4 December 2009; doi:10.1099/ijs.0.020099-0)

76 Chen, Y. G. et al. Psychroflexus sediminis sp. nov., a mesophilic bacterium isolated from salt lake sediment in China. Int. J. Syst. Evol. Microbiol. 59, 569-573 (2009)

77 Wang, Z. et al. Rhodococcus jialingiae sp. nov., an actinobacterium isolated from sludge of a carbendazim wastewater treatment facility. Int. J. Syst. Evol. Microbiol. 60, 378-381 (2010)

78 Liu, Z., Li, Y, Zheng, L. Q., Huang, Y. J. \& Li, W. J. Saccharomonospora marina sp. nov., isolated from an ocean sediment in the East China Sea. Int. J. Syst. Evol. Microbiol., doi:10.1099/ijs.1090.017038-017030 (2010).

79 Qin, S. et al. Saccharopolyspora gloriosae sp. nov., an endophytic actinomycete isolated from the stem of Gloriosa superba L. Int. J. Syst. Evol. Microbiol. 60 (Pt 5), 1147-1151 (2009).

80 Tang, S. K. et al. Saccharopolyspora halophila sp. nov., a novel halophilic actinomycete isolated from a saline lake in China. Int. J. Syst. Evol. Microbiol. 59, 555-558 (2009).

81 Tang, S. K. et al. Saccharopolyspora qijiaojingensis sp. nov., a halophilic actinomycete isolated from a salt lake. Int. J. Syst. Evol. Microbiol. 59, 2166-2170 (2009).

$82 \mathrm{Li}$, J. et al. Saccharopolyspora tripterygii sp. nov., an endophytic actinomycete isolated from the stem of Tripterygium hypoglaucum. Int. J. Syst. Evol. Microbiol. 59, 3040-3044 (2009)

83 Chen, Y. G. et al. Salinicoccus albus sp. nov, a halophilic bacterium from a salt mine. Int. J. Syst. Evol. Microbiol. 59, 874-879 (2009).

84 Chen, Y. G. et al. Salinimicrobium terrae sp. nov., isolated from saline soil, and emended description of the genus Salinimicrobium. Int. J. Syst. Evol. Microbiol. 58, 2501-2504 (2008)

85 Tian, X. P. et al. Sciscionella marina gen. nov., sp. nov., a marine actinomycete isolated from a sediment in the northern South China Sea. Int. J. Syst. Evol. Microbiol. 59, 222-228 (2009)

86 Wang, Y. X. et al. Stackebrandtia albiflava sp. nov. and emended description of the genus Stackebrandtia. Int. J. Syst. Evol. Microbiol. 59, 574-577 (2009).

87 Cai, M. et al. Streptomonospora amylolytica sp. nov. and Streptomonospora flavalba sp. nov., two novel halophilic actinomycetes isolated from a salt lake. Int. J. Syst. Evol. Microbiol. 59, 2471-2475 (2009)

88 Zhao, G. Z. et al. Streptomyces artemisiae sp. nov., isolated from surface-sterilized tissue of Artemisia annua L. Int. J. Syst. Evol. Microbiol. 60, 27-32 (2010).

89 Tian, X. P. et al. Streptomyces nanshensis sp. nov., isolated from the Nansha Islands in the South China Sea. Int. J. Syst. Evol. Microbiol. 59, 745-749 (2009).

$90 \mathrm{Li}$, J. et al. Streptomyces sedi sp. nov., isolated from surface-sterilized roots of Sedum sp. Int. J. Syst. Evol. Microbiol. 59, 1492-1496 (2009).

91 Zhao, X. Q. et al. Streptomyces xinghaiensis sp. nov., isolated from marine sediment. Int. J. Syst. Evol. Microbiol. 59, 2870-2874 (2009).

92 Liao, Z. L. et al. Verrucosispora lutea sp. nov., isolated from a mangrove sediment sample. Int. J. Syst. Evol. Microbiol. 59, 2269-2273 (2009). 
93 Chen, Y. G. et al. Virgibacillus sediminis sp. nov., a moderately halophilic bacterium isolated from a salt lake in China. Int. J. Syst. Evol. Microbiol. 59, 2058-2063 (2009).

94 Tang, S. K., Wu, J. Y., Wang, Y., Schumann, P. \& Li, W. J. Yimella lutea gen. nov., sp. nov., a novel actinobacterium of the family Dermacoccaceae. Int. J. Syst. Evol. Microbiol. 60, 659-663 (2010).

95 Tang, S. K. et al. Zhihengliuella alba sp. nov., and emended description of the genus Zhihengliuella. Int. J. Syst. Evol. Microbiol. 59, 2025-2031 (2009).

96 Pathom-aree, W. et al. Diversity of actinomycetes isolated from challenger deep sediment (10898 m) from the Mariana Trench. Extremophiles 10, 181-189 (2006).

97 Bister, B. et al. Abyssomicin C-a polycyclic antibiotic from a marine Verrucosispora strain as an inhibitor of the p-aminobenzoic acid/tetrahydrofolate biosynthesis pathway. Angew. Chem. Int. Edit. 43, 2574-2576 (2004).

98 Fiedler, H. P. et al. Proximicin A, B and C, novel aminofuran antibiotic and anticancer compounds isolated from marine strains of the actinomycete Verrucosispora. J. Antibiot. 61, 158-163 (2008).

99 Hohmann, C. et al. Caboxamycin, a new antibiotic of the benzoxazole family produced by the deep-sea strain Streptomyces sp NTK 937. J. Antibiot. 62, 99-104 (2009).

100 Navarro-Gonzalez, R. et al. Mars-like soils in the Atacama Desert, Chile, and the dry limit of microbial life. Science 302, 1018-1021 (2003).

101 Kaeberlein, T., Lewis, K. \& Epstein, S. S. Isolating 'uncultivable' microorganisms in pure culture in a simulated natural environment. Science 296, 1127-1129 (2002).

102 Mincer, T. J., Jensen, P. R., Kauffman, C. A. \& Fenical, W. Widespread and persistent populations of a major new marine actinomycete taxon in ocean sediments. Appl. Environ. Microbiol. 68, 5005-5011 (2002).

103 Maldonado, L. A. et al. Diversity of cultivable actinobacteria in geographically widespread marine sediments. Anton. Leeuw. Int. J. G. 87, 11-18 (2005).

104 Rappe, M. S., Connon, S. A., Vergin, K. L. \& Giovannoni, S. J. Cultivation of the ubiquitous SAR11 marine bacterioplankton clade. Nature 418, 630-633 (2002).

105 Giovannoni, S. J. et al. Genome streamlining in a cosmopolitan oceanic bacterium. Science 309, 1242-1245 (2005)

106 Connon, S. A. \& Giovannoni, S. J. High-throughput methods for culturing microorganisms in very-low-nutrient media yield diverse new marine isolates. Appl. Environ. Microbiol. 68, 3878-3885 (2002).

107 Keller, M. \& Zengler, K. Tapping into microbial diversity. Nat. Rev. Microbiol. 2, 141-150 (2004).

108 Bruns, A., Hoffelner, H. \& Overmann, J. A novel approach for high throughput cultivation assays and the isolation of planktonic bacteria. FEMS Microbiol. Ecol. 45, 161-171 (2003).

109 Gich, F., Schubert, K., Bruns, A., Hoffelner, H. \& Overmann, J. Specific detection, isolation, and characterization of selected, previously uncultured members of the freshwater bacterioplankton community. Appl. Environ. Microbiol. 71, 5908-5919 (2005).

110 Zengler, K. et al. Cultivating the uncultured. Proc. Natl Acad. Sci. USA 99, 15681-15686 (2002).

111 Maron, P. A., Ranjard, L., Mougel, C. \& Lemanceau, P. Metaproteomics: a new approach for studying functional microbial ecology. Microbiol. Ecol. 53, 486-493 (2007).

112 Li, X. \& Qin, L. Metagenomics-based drug discovery and marine microbial diversity. Trends Biotechnol. 23, 539-543 (2005).

113 Coates, A. R. \& Hu, Y. Novel approaches to developing new antibiotics for bacterial infections. Br. J. Pharmacol. 152, 1147-1154 (2007).

114 Kennedy, J., Marchesi, J. R. \& Dobson, A. D. W. Metagenomic approaches to exploit the biotechnological potential of the microbial consortia of marine sponges. Appl. Microbiol. Biotechnol. 75, 11-20 (2007).

115 Osburne, M. S., Grossman, T. H., August, P. R. \& MacNeil, I. A. Tapping into microbial diversity for natural products drug discovery-some microbiologists are probing the rich diversity of their backyards instead of going far afield to find useful natural products. ASM News 66, 411-417 (2000).

116 Martinez, A. et al. Genetically modified bacterial strains and novel bacterial artificial chromosome shuttle vectors for constructing environmental libraries and detecting heterologous natural products in multiple expression hosts. Appl. Environ. Microbiol. 70, 2452-2463 (2004)

117 Cowan, D. et al. Metagenomic gene discovery: past, present and future. Trends Biotechnol. 23, 321-329 (2005).

118 Gillespie, D. E. et al. Isolation of antibiotics turbomycin a and B from a metagenomic library of soil microbial DNA. Appl. Environ. Microbiol. 68, 4301-4306 (2002).

119 Bode, H. B., Bethe, B., Hofs, R. \& Zeeck, A. Big effects from small changes: possible ways to explore nature's chemical diversity. Chembiochem 3, 619-627 (2002).

120 Grond, S., Papastavrou, I. \& Zeeck, A. Studies of precursor-directed biosynthesis with streptomyces, part 4 . Novel alpha-L-rhamnopyranosides from a single strain of Streptomyces by supplement-induced biosynthetic steps. Eur. J. Org. Chem. 2002, 3237-3242 (2002).

121 Bills, G. F. et al. Enhancement of antibiotic and secondary metabolite detection from filamentous fungi by growth on nutritional arrays. J. Appl. Microbiol. 104, 1644-1658 (2008).

122 Tormo, J. R. et al. A method for the selection of production media for actinomycete strains based on their metabolite HPLC profiles. J. Ind. Microbiol. Biotechnol. 30, 582-588 (2003).

123 Wang, J. et al. Platensimycin is a selective FabF inhibitor with potent antibiotic properties. Nature 441, 358-361 (2006).
124 Wang, J. et al. Discovery of platencin, a dual FabF and FabH inhibitor with in vivo antibiotic properties. Proc. Natl Acad. Sci. USA 104, 7612-7616 (2007).

125 Zhang, C. W. et al. Isolation, structure, and antibacterial activity of philipimycin, a thiazolyl peptide discovered from Actinoplanes philippinensis MA7347. J. Am. Chem. Soc. 130, 12102-12110 (2008).

126 Llacer, E., Urpí, F.I. \& Vilarrasa, J. Efficient approach to Fluvirucins B2-B5, Sch 38518, and Sch 39185. First synthesis of their aglycon, via CM and RCM reactions. Org. Lett. 11, 3198-3201 (2009).

127 Singh, S. B. et al. Isolation, structure, and antibacterial activities of Lucensimycins DG, discovered from Streptomyces lucensis MA7349 using an antisense strategy. J. Nat. Prod. 72, 345-352 (2009).

128 Zhang, C. et al. Discovery of okilactomycin and congeners from Streptomyces scabrisporus by antisense differential sensitivity assay targeting ribosomal protein S4. J. Antibiot. 62, 55-61 (2009).

129 Bian, J. et al. Amycolatopsis marina sp. nov., an actinomycete isolated from an ocean sediment. Int. J. Syst. Evol. Microbiol. 59, 477-481 (2010).

130 Dai, H. Q. et al. Verrucosispora sediminis sp. nov., a novel cyclodipeptide-producing actinomycete from the South China Sea. Int. J. Syst. Evol. Microbiol. (e-pub ahead of print 18 September 2009; doi:10.1099/ ijs.0.017053-0).

131 Wang, J. et al. Prauserella marina sp. nov., isolated from ocean sediment of the South China Sea. Int. J. Syst. Evol. Microbiol. 60 (Pt 4), 985-989 (2009).

132 You, J. L. et al. Trichoderone, a novel cytotoxic cyclopentenone and cholesta-7, 22diene- 3 beta, 5 alpha, 6 beta-triol, with new activities from the marine-derived fungus Trichoderma sp. J. Ind. Microbiol. Biotechnol. 37, 245-252 (2010).

133 Song, F. et al. Trichodermaketones A-D and 7-O-Methylkoninginin D from the marine fungus Trichoderma koningii. J. Nat. Prod. 73, 806-810 (2009).

134 Bodour, A. A., Drees, K. P. \& Maier, R. M. Distribution of biosurfactant-producing bacteria in undisturbed and contaminated arid southwestern soils. Appl. Environ. Microbiol. 69, 3280-3287 (2003).

135 Ayuso, A. et al. A novel actinomycete strain de-replication approach based on the diversity of polyketide synthase and nonribosomal peptide synthetase biosynthetic pathways. Appl. Microbiol. Biotechnol. 67, 795-806 (2005).

136 Brandao, P. F., Torimura, M., Kurane, R. \& Bull, A. T. Dereplication for biotechnology screening: PyMS analysis and PCR-RFLP-SSCP (PRS) profiling of 16S rRNA genes of marine and terrestrial actinomycetes. Appl. Microbiol. Biotechnol. 58, 77-83 (2002).

137 Dieckmann, R., Graeber, I., Kaesler, I., Szewzyk, U. \& von Dohren, H. Rapid screening and dereplication of bacterial isolates from marine sponges of the Sula Ridge by Intact-Cell-MALDI-TOF mass spectrometry (ICM-MS). Appl. Microbiol. Biotechnol. 67, 539-548 (2005).

138 Maier, T., Klepel, S., Renner, U. \& Kostrzewa, M. Fast and reliable MALDI-TOF MSbased microorganism identification. Nature Methods doi:10.1038/nmeth870 (2006).

139 Antony-Babu, S., Stach, J. E. \& Goodfellow, M. Computer-assisted numerical analysis of colour-group data for dereplication of streptomycetes for bioprospecting and ecological purposes. Antonie Van Leeuwenhoek 97, 231-239 (2010).

140 Larsen, T. O., Smedsgaard, J., Nielsen, K. F., Hansen, M. E. \& Frisvad, J. C. Phenotypic taxonomy and metabolite profiling in microbial drug discovery. Nat. Prod. Rep. 22, 672-695 (2005).

141 Bobzin, S. C., Yang, S. \& Kasten, T. P. LC-NMR: a new tool to expedite the dereplication and identification of natural products. J. Ind. Microbiol. Biotechnol. 25, 342-345 (2000).

142 Wolfender, J. L. et al. Evaluation of Q-TOF-MS/MS and multiple stage IT-MSn for the dereplication of flavonoids and related compounds in crude plant extracts. Analusis 28, 895-906A (2000).

143 Gu, J. Q., Wang, Y. H., Franzblau, S. G., Montenegro, G. \& Timmermann, B. N. Dereplication of pentacyclic triterpenoidls in plants by GC-EI/MS. Phytochem. Anal. 17, 102-106 (2006).

144 Konishi, Y. et al. Molecular formula analysis by an MS/MS/MS technique to expedite dereplication of natural products. Anal. Chem. 79, 1187-1197 (2007).

145 Lambert, M., Staerk, D., Hansen, S. H., Sairafianpour, M. \& Jaroszewski, J. W. Rapid extract dereplication using HPLC-SPE-NMR: analysis of isoflavonoids from Smirnowia iranica. J. Nat. Prod. 68, 1500-1509 (2005).

146 Nielsen, K. F. \& Smedsgaard, J. Fungal metabolite screening: database of 474 mycotoxins and fungal metabolites for dereplication by standardised liquid chromatography-UV-mass spectrometry methodology. J. Chromatogr. A 1002, 111-136 (2003).

147 Bradshaw, J. et al. A rapid and facile method for the dereplication of purified natural products. J. Nat. Prod. 64, 1541-1544 (2001).

148 Bitzer, J. et al. Accelerated dereplication of natural products, supported by reference libraries. Chimia 61, 332-338 (2007).

149 Lang, G. et al. Evolving trends in the dereplication of natural product extracts: new methodology for rapid, small-scale investigation of natural product extracts. J. Nat. Prod. 71, 1595-1599 (2008)

150 Mitova, M. I. et al. Evolving trends in the dereplication of natural product extracts. 2. The isolation of chrysaibol, an antibiotic peptaibol from a New Zealand sample of the mycoparasitic fungus Sepedonium chrysospermum. J. Nat. Prod. 71, 1600-1603 (2008).

151 Thakur, N. L. et al. Marine molecular biology: an emerging field of biological sciences. Biotechnol. Adv. 26, 233-245 (2008).

152 Hugenholtz, P., Goebel, B. M. \& Pace, N. R. Impact of culture-independent studies on the emerging phylogenetic view of bacterial diversity. J. Bacteriol. 180, 4765-4774 (1998). 
153 Hentschel, U. et al. Isolation and phylogenetic analysis of bacteria with antimicrobial activities from the Mediterranean sponges Aplysina aerophoba and Aplysina cavernicola. FEMS Microbiol. Ecol. 35, 305-312 (2001).

154 Amann, R. \& Ludwig, W. Ribosomal RNA-targeted nucleic acid probes for studies in microbial ecology. FEMS Microbiol. Rev. 24, 555-565 (2000).

155 Stach, J. E. et al. Statistical approaches for estimating actinobacterial diversity in marine sediments. Appl. Environ. Microbiol. 69, 6189-6200 (2003)

156 Stach, J. E., Maldonado, L. A., Ward, A. C., Goodfellow, M. \& Bull, A. T. New primers for the class Actinobacteria: application to marine and terrestrial environments. Environ. Microbiol. 5, 828-841 (2003).

157 Taylor, M. W., Schupp, P. J., de Nys, R., Kjelleberg, S. \& Steinberg, P. D. Biogeography of bacteria associated with the marine sponge Cymbastela concentrica. Environ. Microbiol. 7, 419-433 (2005).

158 Taylor, M. W., Schupp, P. J., Dahllof, I., Kjelleberg, S. \& Steinberg, P. D. Host specificity in marine sponge-associated bacteria, and potential implications for marine microbial diversity. Environ. Microbiol. 6, 121-130 (2004).

159 Taylor, M. W., Radax, R., Steger, D. \& Wagner, M. Sponge-associated microorganisms: evolution, ecology, and biotechnological potential. Microbiol. Mol. Biol. Rev. 71, 295-347 (2007).

160 Zhi, X. Y., Li, W. J. \& Stackebrandt, E. An update of the structure and 16S rRNA gene sequence-based definition of higher ranks of the class Actinobacteria, with the proposal of two new suborders and four new families and emended descriptions of the existing higher taxa. Int. J. Syst. Evol. Microbiol. 59, 589-608 (2009).
161 Lipinski, C. A., Lombardo, F., Dominy, B. W. \& Feeney, P. J. Experimental and computational approaches to estimate solubility and permeability in drug discovery and development settings. Adv. Drug Deliv. Rev. 46, 3-26 (2001).

162 Baltz, R. H. Daptomycin: mechanisms of action and resistance, and biosynthetic engineering. Curr. Opin. Chem. Biol. 13, 144-151 (2009).

163 Borel, J. F. History of the discovery of cyclosporin and of its early pharmacological development. Wien. Klin. Wochenschr. 114, 433-437 (2002).

164 Leeson, P. D. \& Davis, A. M. Time-related differences in the physical property profiles of oral drugs. J. Med. Chem. 47, 6338-6348 (2004).

165 O'Shea, R. \& Moser, H. E. Physicochemical properties of antibacterial compounds: implications for drug discovery. J. Med. Chem. 51, 2871-2878 (2008).

166 Young, K. et al. Discovery of FabH/FabF inhibitors from natural products. Antimicrob. Agents Chemother. 50, 519-526 (2006).

167 Pathania, R. et al. Chemical genomics in Escherichia coli identifies an inhibitor of bacterial lipoprotein targeting. Nat. Chem. Biol. 5, 849-856 (2009).

168 Ayuso-Sacido, A. \& Genilloud, O. New PCR primers for the screening of NRPS and PKS-I systems in actinomycetes: detection and distribution of these biosynthetic gene sequences in major taxonomic groups. Microbiol. Ecol. 49, 10-24 (2005).

169 Ansari, M. Z., Yadav, G., Gokhale, R. S. \& Mohanty, D. NRPS-PKS: a knowledgebased resource for analysis of NRPS/PKS megasynthases. Nucleic Acids Res. 32, W405-W413 (2004).

170 Bergmann, S. et al. Genomics-driven discovery of PKS-NRPS hybrid metabolites from Aspergillus nidulans. Nat. Chem. Biol. 3, 213-217 (2007). 